Article

\title{
Farmers' Perceptions and Factors Influencing the Adoption of No-Till Conservation Agriculture by Small-Scale Farmers in Zashuke, KwaZulu-Natal Province
}

\author{
Njabulo Lloyd Ntshangase, Brian Muroyiwa and Melusi Sibanda * \\ Department of Agriculture, University of Zululand, Private Bag X1001, KwaDlangezwa 3886, South Africa; \\ njabulo.ntshangase@kzndard.gov.za (N.L.N.); MuroyiwaB@unizulu.ac.za (B.M.) \\ * Correspondence: SibandaM@unizulu.ac.za; Tel.: +27-35-902-6068
}

Received: 6 November 2017; Accepted: 15 January 2018; Published: 23 February 2018

\begin{abstract}
The adoption of conservation agriculture among small-scale farmers is still low despite the proven economic and environmental benefits of the technology. This study was conducted in Ingwe Municipality in Kwa-Zashuke, Ward 8, in KwaZulu-Natal province. The main aim of the study was to determine the factors that influence the adoption of no-till conservation agriculture (CA) in the study area and to explore farmers' perceptions of no-till CA and the impact of no-till CA on maize yield. A quantitative approach employing a cross-sectional design was used to gather data. Stratified random sampling was employed and a total of 185 small-scale farmers ( 97 adopters and 88 non-adopters) were sampled. Data analysis was done through descriptive and inferential statistics and econometric modeling using the logistic regression model. Findings show that farmers' positive perceptions were positively correlated with higher maize yields. While an increase in extension visits, age, education and farmers' positive perceptions significantly increased the likelihood of a farmer adopting no-till CA, an increase in land size was negatively related to no-till CA adoption. The findings confirm the important role of extension in the promotion of no-till CA, particularly the intensity of the extension services. The study recommends a deliberate effort by all stakeholders to promote the participation of young people in farming and tailor-make current no-till CA programs to suit the illiterate households. The capacity of extension programs to adequately support farmers should be enhanced through improvements in extension services. There is also need to change people's mindsets and the way they view no-till CA.
\end{abstract}

Keywords: adoption; conservation agriculture; no-till; small-scale farmer

\section{Introduction}

The recognition of no-till conservation agriculture (CA) as a solution to food security, biodiversity and water scarcity challenges is gaining momentum worldwide [1]. Some research and development organizations now view the technology as one of the solutions to the adverse effects of climate change [1]. Although the role of no-till as a climate-smart solution is being questioned [1-3], the technology still remains one of the solutions to address some of the challenges affecting small-scale farming in Africa [1]. Amongst the major challenges faced by small-scale farmers are soil erosion and the efficiency in which the limited water is used [4-6]. The situation is further worsened by climate change effects such as persistent droughts, which are currently being experienced in the sub-Saharan region [5]. Agriculture remains one of the most important components of most African economies [7] and its success is based on the foundation of good soils and efficient utilization of the available water resources, among other factors. In this regard, no-till CA plays an integral role in minimizing soil 
disturbance and water loss [6]. However, the impact of the technology will only be realized if most small-scale farmers accept and adopt the technology. Conservation agriculture is defined as soil management practices that minimize the disruption of the soil's structure, composition, and natural biodiversity and that include very little soil disturbance through tillage, permanent organic soil cover, and diversified crop rotations. For the purpose of this paper, no-till CA refers to drilling, zero-till, slot-planting, and/or chemical tillage. In no-till CA, planting takes place in unprepared soil. It is a sequence of operations that reduce erosion caused by mechanically killing the vegetation on the field through the use of herbicides. The minimum disturbance of soil occurs at planting when seed and fertilizer are put into the soil. The crop is planted directly into the preceding year's crop residue, hence retaining more than fifty percent of the residue on the soil surface for the entire season.

It has since been argued that traditional cultivation systems employing intensive soil tillage result in soil degradation and reduced crop yields [8,9]. The consequences are further exacerbated by the negative effects of monoculture cereal production and overgrazing in communal areas [10]. If small-scale farming is to survive and sustainable agriculture is to be achieved by farmers, then the patterns of agricultural production and management must evolve and new farming practices must be implemented [10-12]. In South Africa, research on no-till agriculture systems started in the 1970s [13]. Forms of no-tillage are practiced in South Africa's total cultivatable area. However, the adoption is mostly limited to commercial farmers producing grain crops and sugarcane. The practical application on a commercial farm scale was initially hampered by the local unavailability of suitable no-till planting equipment and a hesitancy to adopt the technique [13]. The strict regulations in the South African maize industry also undoubtedly influenced farmers to continue practicing conventional moldboard plough-based production methods. Although there may be many successful farmers in South Africa who practice no-till CA, no-till CA in the province of KwaZulu-Natal (KZN) in South Africa, specifically at Zashuke, was not common and was introduced by the Department of Agriculture and Rural Development using extension officers to cascade information particularly to small-scale farmers. In America, the early contribution of innovative farmers was extremely important in establishing no-till as a new technique [13]. Unfortunately, without farmer acceptance of the method, research findings will get no further than the libraries where these reports are stored.

It has taken much longer for no-till to become accepted in South Africa than elsewhere but now that the agricultural markets have been deregulated and production costs have increased, innovative farmers have been forced to seriously consider alternative production methods [13]. Many farmers in rural areas are faced with the problems of low yields, low product quality, and poor sustainability and profitability [14]. A reliance on poor methods of practicing agriculture is increasing land degradation [15]. According to Food and Agricultural Organisation of the United Nations (FAO) [16], many subsistence crop production system soils in sub-Saharan Africa are depleted and have poor nutrient content, resulting in low agricultural productivity. Rural communities in South Africa face similar challenges. Du Preez [15] reported that the degradation of soil as a result of land uses poses a threat to sustainable agriculture in South Africa. Conservation agriculture provides a strategy for addressing soil degradation [17].

The literature highlights several benefits of no-till CA, amongst which are an improvement in soil fertility, labour savings, improved efficiency in water use, an increase in productivity and environmental sustainability [16-18]. However, despite these benefits, there has been low adoption or quick dis-adoption of no-till CA among small-scale farmers in South Africa [19]. Most small-scale farmers revert to or continue to use conventional tillage methods. There are several factors that influence the uptake of technological innovation, one of which is farmers' perceptions. McRoberts and Rickards [20] indicated that the perceptions and views of the community are at the centre of the adoption of conservation agriculture technologies. To date, this study is not aware of any research study conducted in South Africa focusing on farmers' perceptions and its impact on the adoption of no-till CA. However, studies in countries such as Australia, Pakistan and Tanzania, among others, have explored the influence of farmers' perceptions on the adoption of no-till CA [16,21,22]. Indeed, Sheik et al. [21] 
and D'Emden et al. [22] showed that farmers' perceptions do influence their adoption decisions. Hence, the focus of this research attempted to understand the factors affecting the adoption of no-till CA among small-scale farmers, including farmers' perceptions of technology. This knowledge will be critical for government and its partners in designing effective strategies for promoting CA in South Africa's rural communities. This study was motivated by the need to understand the reasons for non-adoption or dis-adoption of no-till CA among small-scale farmers in South Africa. Such an understanding is able to show the opportunities available to increase the use of no-till among small-scale farmers in South Africa. The study has the potential to generate useful information that could contribute to the improvement of household food security through increased agricultural productivity using sustainable farming practices. The study also explores the factors that influence the adoption of no-till production practice; understanding such factors is paramount in designing relevant support systems that will promote sustainable farming practices such as no-till CA. The study is also important in up-scaling the efforts to encourage soil management strategies that are environmentally friendly.

\section{Methodology}

\subsection{Description of the Study Area}

The area of study was Ward 8 under the Ingwe Local Municipality, which is in the Sisonke District of the province of KwaZulu-Natal. Ingwe Local Municipality is among five municipalities in the Sisonke District. It has 11 wards that are under 12 tribal authorities of the Ingonyama Trust Lands. These are Madzikane-Bhaca, Isibonela Esihle, Amakuze, Sizanani, Umacala-Gwala, Zashuke, Qadi, Bidla, Vukani, Amangwane, KwamaFuze and Vezakuhle traditional authorities [23]. Ward 8 under the Zashuke tribal authority was selected for the study since it was the ward targeted for the government-supported dryland maize CA pilot project under the municipality in 2004. Not all farmers participated in this pilot project. Hence, it is possible to compare small-scale farmers who adopted and those who did not adopt no-till CA in the ward. Figure 1 shows the location of Ingwe Municipality in the Sisonke District.

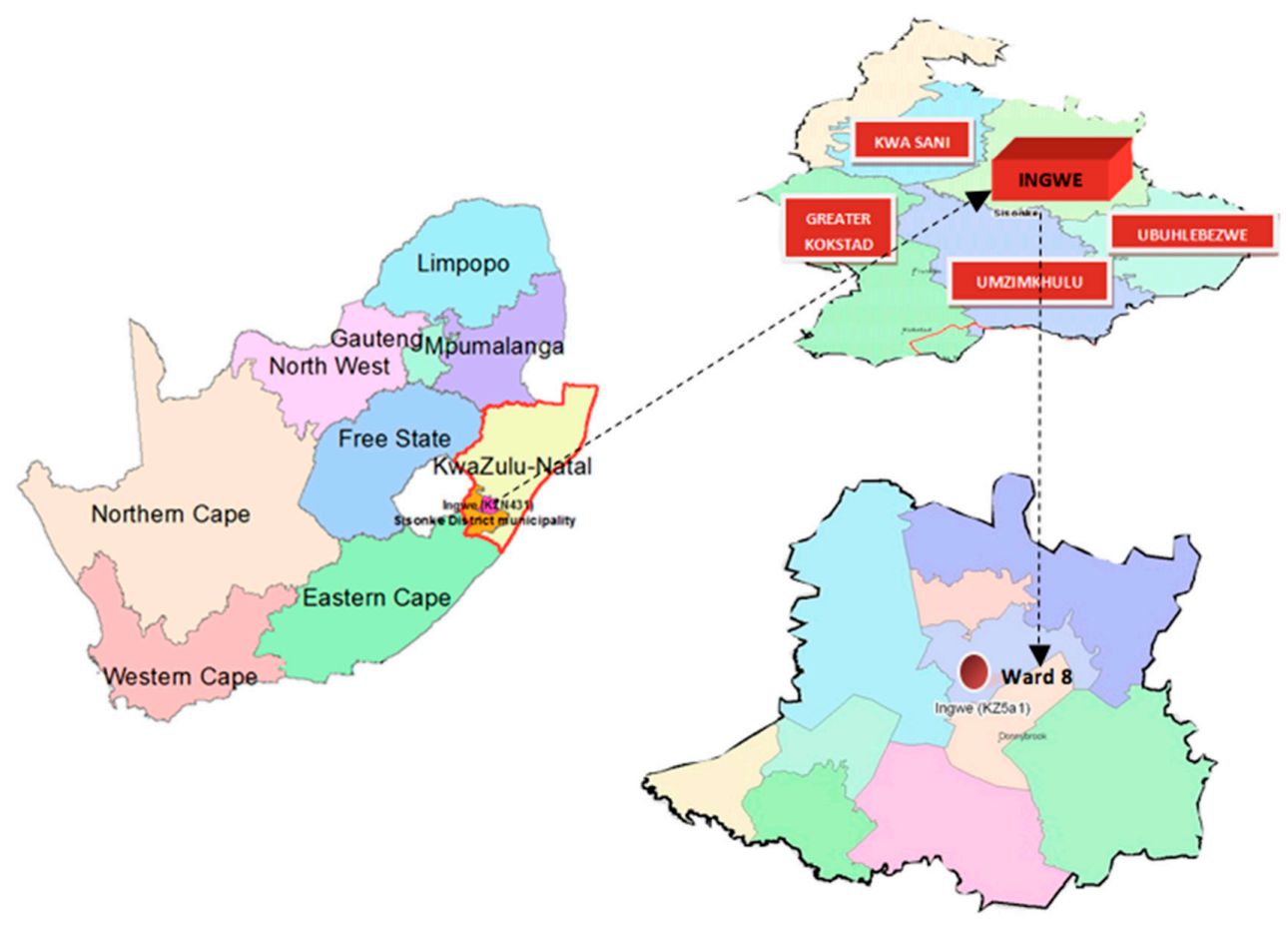

Figure 1. Location of Ward 8 in Ingwe Local Municipality in relation to the province of KwaZulu-Natal $(\mathrm{KZN})$ in South Africa. Source: Adapted from Rasmo (2009). 
Ingwe Municipality covers an estimated $1970 \mathrm{~m}^{2}$ and has an altitude that ranges from $2083 \mathrm{~m}$ in the northeast (Mahwaqa Peak) to $450 \mathrm{~m}$ in the southeast (Umkomaas Valley). Much of the land in the municipality is undulating. Flatter land is found in small plateaus in the western highland areas while the steep valleys are within the catchment areas of the ward [23,24]. The climatic regions of Ingwe can be divided into two distinct areas: the highland region and the moist upland climatic region. Three temperature zones are found in the municipality with the higher areas in the west having a cooler temperature while lower regions in the east are warmer. In the winter, the temperature ranges from below zero in the western regions to approximately $5{ }^{\circ} \mathrm{C}$ in the eastern regions. In the summer, which is the agricultural production season, the temperature ranges from the low to high thirties in the west and east, respectively, which means that evapotranspiration is quite high in the area. This makes improved efficiency of water use and moisture conservation important for agricultural production. The mean annual rainfall ranges from $700 \mathrm{~mm}$ to $1200 \mathrm{~mm}$ [24]. The soils in Ingwe are considered to be low in fertility and are highly erodible. This affects agricultural productivity, particularly for small-scale farmers who cannot afford adequate amounts of recommended inorganic fertilizers to boost their harvests. Farming practices that do not affect the soil structure but rather improve the soil quality are therefore important for the survival of most rural communities in Ingwe.

\subsection{Research Framework}

The study is grounded in three different theoretical perspectives of technology adoption that have been used in past studies: innovation diffusion theory; economic constraints; and adopter perceptions perspectives $[25,26]$. Information dissemination is at the centre of the innovation diffusion theoretical perspectives, and adoption is viewed as a series of linear stages from knowledge acquisition to persuasion, decision, implementation and finally confirmation stages [26]. The economic constraints theoretical perspective states that adoption is influenced by access to economic resources and indicates that a lack of access to these resources affects technology adoption. The theory identifies the complex diversity and differences in small-scale farmers regarding access to these resources and postulates that asymmetric distribution of these resources could lead to this heterogeneity [25]. The adopter-perceptions theoretical perspective identifies farmers' perceptions as being key to the adoption of farming technology [25]. This study integrates the three theories to develop a conceptual understanding of the research problem.

Conceptually, Lugandu [17] stated that the decision to adopt or not adopt CA is a function of farmers' perceptions of CA compared to other farming practices or technologies. There are several reasons why farmers may adopt a new farming technology (FAO, 2001). Some farmers may be rational in their behaviour and their perceptions may be influenced by the information available to them, their socioeconomic situation and farm enterprises [17]. Adoption is defined by Feder et al. [27] as the extent to which farmers put into practice a new innovation in the future, given adequate information about the technology and the potential benefits. Several variables have been identified in the literature as determining the level of adoption. These include human capital, credit constraints, risk, farm size, labour availability, land tenure, livestock assets, agricultural training, interactions with extension and input supply [16,27-29]. Understanding these variables and how they influence adoption are important in developing strategies for promoting the use of no-till CA. Figure 2 shows the conceptual framework on adopting a new technology by farmers. 


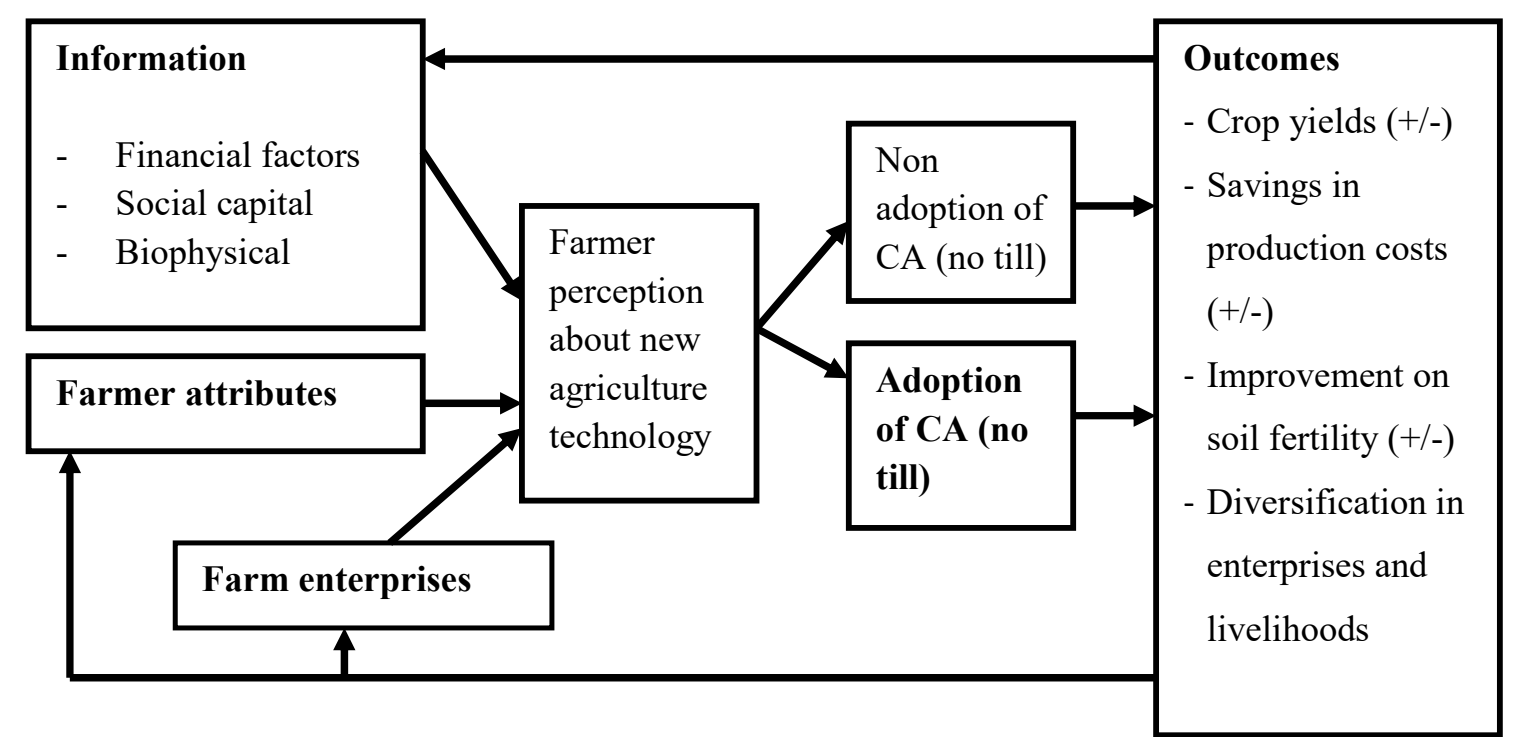

Figure 2. Conceptual framework. Source: Adapted from Lugandu (2013).

\subsection{Research Design}

A research design provides a context within which a study is conducted [30]. A cross-sectional study design was used to assess farmers' perceptions of no-till CA and to determine the factors affecting the adoption of no-till CA among small-scale farmers. A cross-sectional study design concerns data collection of at least two variables at a given point in time with the objective of assessing the existence of a relationship between the variables in question [31]. A questionnaire survey is usually the best method of data collection in such a design. The methodology that was employed in the study was quantitative, involving the collection of data using a structured questionnaire. A quantitative survey allows for the use of econometric models to determine the influence of different factors on no-till CA adoption.

\subsection{Description and Selection of Participants}

In 2004, the Department of Agriculture in KwaZulu-Natal implemented a dryland maize project. The project aimed at promoting no-till CA among rural small-scale farmers. The participants or respondents of this study were selected from the members of that project and also those who did not actively participate. Adopters in this study were the farmers who participated in the no-till CA under the dryland maize project. Most of these farmers are still practicing no-till CA, although on a smaller scale. Although there may be other farmers who adopted the no-till CA at their own volition and expense without being participants of the dryland maize project, including them in this study became an obstacle as obtaining a complete sampling list (frame) of those farmers proved difficult. Non-adopters are farmers who were aware of the project and some even participated in the project (went through training) but did not adopt no-till CA for various reasons. The study excluded a small group of dis-adopters, namely those farmers who had adopted at first and then stopped. The focus of the study was to understand why farmers adopt or do not adopt no-till CA. The assumption here is that farmers first decide whether to adopt a new technology or not. Once farmers adopt that technology, they may decide to either continue or discontinue using it, which then brings the concept of dis-adoption. Dis-adopters were, therefore, excluded from the study because they bring a completely different dimension to the research on adoption, which was not the focus of this study. However, it would be interesting to include dis-adopters in a future study. Farmers were identified through registers obtained from the Department of Agriculture and Environmental Affairs (DAEA) in the district. 


\subsection{Sample Design and Data Collection}

The study used a probability sampling method to select the study sample. It employed stratified random sampling to determine the households that participated in the questionnaire survey. The study sample was divided into two groups of farmers: those who adopted (adopters) and those who did not adopt (non-adopters). The sampling unit was the household member undertaking the farming activities in the household, and the sampling frame consisted of farmers who were exposed to no-till conservation agriculture under the dryland maize project in Kwa-Zashuke Ward 8. Hardon et al. [32] stated that stratified random sampling has an advantage in that it reduces the cost of collecting data from larger groups of the population by allowing researchers to make usable conclusions using a large sample taken from a small group. Registers from the DAEA showed that at least 200 farmers in the district had participated in the no-till CA project. The study used the formula provided by Krejcie and Morgan [33] to determine the optimal sample size. A sample of at least 132 farmers was determined. This was based on the population of 200 farmers who took part in the project. In the study, the final sample was larger, constituting 185 farmers (52\% adopters of no-till CA and $48 \%$ non-adopters of no-till CA). No incentives were given to farmers to participate in the study. However, it was difficult to exclude other farmers from the survey given their interest in participating. The interest from adopters of no-till CA to participate in the study was probably based on their experience. Experience is a very important aspect to farmers in adopting a particular technology, especially if the technology proved worthwhile to them. Initially, the plan was to have an equal number of participants from each stratum so that there was an equal chance (probability) of selecting each respondent from the two groups. However, this was not possible as some non-adopters were either not available or not willing to participate in the survey. All of the adopters were willing to participate, probably because they are very comfortable with their current farming practices. Farmers may be reluctant to change especially when they are not convinced about what they are being encouraged to adopt; therefore, they may not give any thought to improving their lives.

Data were collected using questionnaires. Questionnaires were prepared and administered on a house-to-house basis. The questionnaire was translated into the local isiZulu language for ease of implementation. The questionnaire was pretested before it was finalized. Pretesting was done to refine the questionnaire and check on important issues such as the time taken to complete the questionnaire and the adequacy and appropriateness of the questions. Time considerations were very important in the questionnaire administration given the level of farmer fatigue in the study area. Pretesting was done in the same community with a few farmers who did not take part in the main survey.

Data collection was conducted by two well-trained enumerators who were known in the Ingwe Local Municipality area. As part of their training, the enumerators participated in the pretesting, which also gave them an opportunity to practice asking the questions. The data collection period was two weeks in the month of December 2015.

\subsection{Data Analysis}

The study utilized descriptive statistics and inferential analysis to investigate farmers' perceptions regarding the influence of no-till CA on product yield. A binary logistics regression model was employed to determine the factors influencing the adoption of no-till CA in Kwa-Zashuke Ward 8. Econometrics software was utilized to achieve this. A brief description is given below of the data analysis methods that were used.

\subsubsection{Descriptive and Inferential Analysis}

Description of the variables used in the logistic regression model to show the perceptions of farmers on no-till CA was done using descriptive statistics, t-statistics and Pearson correlations. The results of this analysis are presented using frequency tables, cross-tabulations, and graphs. 
For continuous variables, mean and standard deviations are reported while for categorical variables, percentages are reported.

\subsubsection{Binary Logistic Model}

The study applied a binary logistic regression model to analyze the factors influencing the adoption of no-till CA. The model was adapted from similar studies; for example [21,29,34-36]. The binary model is motivated by the fact that, when faced with a decision regarding an innovation, a farmer either adopts or rejects the technology [36,37]. The logistic regression model was chosen because there is widespread literature showing that farmer adoption decisions can be analyzed using logistic regression. The dependent variable for this study was the farmer being an adopter or a non-adopter of no-till CA with a value of 1 (if the farmer was an adopter of no-till CA) and/or 0 (for a non-adopter of no-till CA). The logistic model predicts the logit of the response variable (adoption of no-till CA) from the independent variable(s). The likelihood of the farmer being an adopter of no-till CA is predicted by odds $(Y=1)$; that is, the ratio of the probability that $Y=1$ to the probability that $Y \neq 1$ :

$$
\text { Odd } Y=\frac{P(Y=1)}{(1-P(Y=1))}
$$

The binary logistic regression model is specified as follows (Equation (2)):

The logit $(Y)$ is given by the natural log of Odds;

$$
\ln \left(\frac{p\left(Y_{i}=1\right)}{\left(1-p\left(Y_{i}=1\right)\right)}\right)=\log \text { Odds }=\operatorname{Logit}(Y)
$$

This can be expanded as

$$
\operatorname{Logit}(Y)=\alpha+\sum \beta_{1} X_{1}+\sum \beta_{2} X_{2}+\ldots+\sum \beta_{n} X_{n}+\varepsilon_{i}
$$

where $Y=$ dependent variable (adoption) with $1=$ adopters and $0=$ otherwise; $\alpha=$ intercept; $\beta_{1}, \ldots ., \beta_{n}$ $=$ coefficients of the independent variables; $X_{1}, \ldots, X_{n}=$ the independent variables; $P(p)=$ probability of adopting no-till CA; $1-P=$ probability that a farmer does not adopt no-till $\mathrm{CA}$; and $\ln =$ natural $\log$.

With the independent variables of this model $\left(X_{1}=\right.$ age, $X_{2}=$ gender, and so on), logistic regression for 'ADOPTION' in the study is expressed in the following form:

$$
\log \text { it }(\text { Adoption })=\ln \left(\frac{p}{1-p}\right)=\alpha+\beta_{1} \text { age }+\beta_{2} \text { gender }+\beta_{3} \text { edu }+\beta_{4} \text { land }+\beta_{5} \text { income }+\beta_{6} \text { ext }+\beta_{7} \text { CA pro }+\beta_{8} \text { EcoAct }
$$

The criterion used to assess the overall significance of the binary logit model was the log-likelihood ratio following Greene [38]. The variance inflation factors (VIF) were used to inspect the level of multicollinearity between the independent variables. The classification accuracy indicated the appropriateness of the model in predicting the adoption of no-till CA given the independent variables in question. The explanatory variables used in the binary logit model were obtained from the literature, and the model indicated the significance of these variables in the adoption of the no-till CA technology.

\section{Independent Variables and Their Expected Outcomes}

The independent variables that were used in the study are given in Table 1 and the choice of independent variables was guided by the literature. Table 1 shows the independent (explanatory) variables, their description and the expected outcome in relation to the dependent variable. 
Table 1. Explanatory variables, description and the expected outcome.

\begin{tabular}{|c|c|c|c|}
\hline Variable & Description and Measurement Type & Variable Type & $\begin{array}{c}\text { Expected } \\
\text { Outcome } \\
(+/-)\end{array}$ \\
\hline Age & Age of farmer (years) & continuous & + \\
\hline Gender & Gender of farmer $(1=$ female $0=$ male $)$ & categorical & + \\
\hline Education & Number of years of formal education & continuous & + \\
\hline $\begin{array}{l}\text { Economically active } \\
\text { members }\end{array}$ & Proportion of household members economically active & continuous & + \\
\hline Experience in farming & Experience in farming & continuous & + \\
\hline Training & $\begin{array}{l}\text { Training received on no-till CA }(1=\text { Yes received, } \\
0=\text { otherwise) (Dummy) }\end{array}$ & categorical & + \\
\hline Extension & $\begin{array}{l}\text { Frequency of extension visits per month }(1=\text { does not visit, } \\
\qquad 2=\text { once, } 3=\text { twice, } 4=\text { more than twice })\end{array}$ & categorical & + \\
\hline Access to credit & $\begin{array}{l}\text { Have access to credit for agriculture }(1=\text { Yes received, } \\
\qquad 0=\text { otherwise) (Dummy) }\end{array}$ & categorical & + \\
\hline Promotion of no-till & $\begin{array}{l}\text { Perception on promotion of no-till CA }(1=\text { strongly agree, } \\
2=\text { agree, } 3=\text { neutral, } 4=\text { disagree, } 5 \text { strongly disagree })\end{array}$ & categorical & + \\
\hline Land size & Land size of arable land (Ha) & continuous & - \\
\hline Income & Household income & continuous & - \\
\hline
\end{tabular}

The independent variable of age, measured as a continuous variable, can be used as a proxy for experience in farming. Age was expected to positively influence the adoption of no-till CA, meaning that older farmers would tend to adopt no-till CA more frequently than younger farmers. Gender was measured as a categorical variable (dummy) coded with 1 if female and 0 if male. Adoption was expected to be higher among females compared to males since females are the ones most involved with household farming activities in rural areas. Education was measured as a continuous variable (number of years of formal education the farmer had). The assumption was that adoption increases with more years of schooling. Thus, a more educated person is expected to appreciate new ideas better and quicker than their counterparts (the less educated farmers). The variable economically active members were measured as a continuous variable. Instead of using family size, the study used economically active members of the household as a proxy for labour availability. This is because of the realization that higher family size does not necessarily translate to more family labour in the household. The variable economically active members were computed as the difference between total family size and the number of dependents in the household. Dependents are defined as members who were 15 years and younger and those who were 65 years and older. The study postulated that households with a larger proportion of economically active household members would adopt no-till CA compared to those with smaller proportions of economically active members. Experience in farming was measured as a continuous variable. The variable used a proxy to measure farmers' knowledge about farming, which is acquired over time. It was assumed that experienced farmers have a higher probability of adopting no-till CA compared to those with little experience in farming. Access to working capital is a challenge for small-scale farmers. The variable was measured in the study by asking farmers if they had access to credit loans. Access to credit was measured as a categorical (dummy) variable with a yes or no answer. Adoption was expected to be high among farmers with access to credit compared to those without. The variable perceptions about the promotion of no-till CA were used to measure farmers' perceptions of no-till CA. It was measured on a Likert scale of 1-5 coded with 1 if strongly agreed, 2 if agreed, 3 if neutral, 4 if disagreed, and 5 if strongly disagreed. Expectations were that the higher the scale, the more likely that a farmer would adopt no-till CA. The variable received training in CA (dummy variable) was measured by asking farmers whether they had previously been trained in CA. Access to training is a key aspect of technology adoption, especially 
where new ideas are introduced. The study postulated that adoption would be higher among those who received training compared to those who did not receive any training. The frequency of extension visits (number of extension visits per month) was used to measure both access to and intensity of extension services. No-till CA adoption was expected to be higher with increased extension contacts. The size of land cultivated was recorded in hectares (measured as a continuous variable). The literature indicates that small-scale farmers with smaller sizes of land are expected to adopt no-till CA compared to those who cultivate larger sizes of land [17]. The income variable was collected as a proxy of the working capital available for use in farming. Each farmer was asked to indicate their estimated income per month in South African Rands (ZAR). This income had to be calculated from all their livelihood sources. Income was measured as a continuous variable and it was expected that farmers with a higher income would be more likely to adopt no-till CA compared to those with a lower income.

\section{Results}

\subsection{Summary of Socioeconomic Characteristics of Respondents}

In general, the study found that more male farmers (54\%) were adopters of no-till CA than female farmers $(46 \%)$. Education levels among both types of farmers were low and there was a significant difference between the two, meaning that education could be a potential determinant in the adoption of no-till CA. No-till conservation adopters had a higher mean education level (3.7) compared to non-adopters (2.6). Other studies have shown that higher education levels increase the chances of adopting no-till CA because educated farmers are more likely to easily understand and be receptive to new technology or innovations $[39,40]$. There was no significant difference between the age of no-till adopters and non-adopters. The average age of adopters was slightly higher; 63 years compared to non-adopters (62 years). In general, the results show that farmers who participated in the study were elderly. This conforms to the demographic structure of South Africa where most of the elderly are found in the rural areas and young people in the urban areas [41,42]. Although adopters had larger household sizes compared to non-adopters, the results have shown that this does not translate to more labour availability on the farm but does reveal high levels of economic burden in such households. It is expected that households with a higher number of household members are more likely to adopt no-till CA since it is assumed that larger families have more labour available for farm operations such as weeding, which is critical in no-till CA [43]. However, this assumption does not always hold since labour availability depends not only on how large a household is but also on the ages and type of persons in that household [44]. In this study, the proportion of economically active members was slightly higher for non-adopters (0.28) compared to adopters (0.23) even though the household size was higher for adopters compared to non-adopters.

There was a significant difference in land, income, access to credit, access to extension, group membership and training on CA. The size of land cultivated by farmers was significantly different between no-till CA adopters and non-adopters with a $p$-value of less than 0.05 . Farmers who did not adopt no-till CA cultivated bigger mean land sizes compared to adopters. Income levels between no-till CA adopters and non-adopters were statistically different at $5 \%$. The size of land cultivated by farmers was significantly different between no-till CA adopters and non-adopters with a $p$-value of less than 0.05. Adopters had a mean higher income of R1 746 compared to R1 271 for non-adopters. Higher incomes are associated with higher levels of adoption rates [21,45]. Higher income means that the farmer can buy inputs for farming and hence can engage in conservation agriculture. However, although most CA technologies are cheaper (low external input), no-till CA was not readily adopted by low-income households probably because these households did not have full knowledge about it or its benefits and / or probably perceived it to be costly because of their lack of knowledge. Again, further discussion with farmers revealed that small-scale farmers generally lack infrastructure such as fencing material, which requires some income to purchase. 
The findings of the study suggest that non-adopters of no-till CA cultivated larger pieces of land, had lower incomes and limited access to extension and credit. The top three sources of income of the adopters of no-till CA were government grants, farming and piece work. The majority $(78 \%$ and $51 \%$ ) of the adopters indicated that they derived their income from government social grants and farming, respectively, as compared to the non-adopters. Non-adopters did not necessarily rely on crop farming as a source of income. Further probing revealed that government grants describe mostly social support grants received by households that qualify for child, disability and old person support from the Department of Social Development. On the other hand, more (65\%) non-adopters of no-till CA indicated that they relied on piece work to earn an income. Table 2 shows the results of extension visits, access to credit, awareness of CA and training. According to the results in Table 2, adopters of no-till CA had more access to extension services compared to non-adopters. Non-adopters of no-till CA also did not participate in groups and few received training on CA. All these socioeconomic factors could be important determinants of no-till CA adoption for farmers in Ingwe, Ward 8. Farmer perceptions on the promotion of no-till CA were also positively related to maize yield.

Table 2. Other socioeconomic characteristics between adopters and non-adopters.

\begin{tabular}{ccccc}
\hline Variable & & Adopters (\%) & Non-Adopters (\%) & Chi-Square \\
\hline & No visits & 3.1 & 30.7 & \\
Extension visits & One visit & 18.6 & 26.1 & $38.8^{* * *}$ \\
(per month) & Two visits & 22.7 & 23.9 & \\
& 3 and above visits & 55.7 & 19.3 & \\
& Total & $\mathbf{1 0 0}$ & $\mathbf{1 0 0}$ & \multirow{2}{*}{$4.91^{* *}$} \\
Access to credit & Yes & 10.3 & 2.3 & \\
(Yes/No) & No & 89.7 & 97.7 & $11.65^{* *}$ \\
& Total & $\mathbf{1 0 0}$ & $\mathbf{1 0 0}$ & $177.1^{* * *}$ \\
Awareness of CA & Aware & 100 & 11.4 & \\
(Aware/Not aware) & Not aware & 0 & $\mathbf{1 0 0}$ & \\
\hline \multirow{2}{*}{ Received training } & Total & $\mathbf{1 0 0}$ & 2.3 & \\
on CA (Yes/No) & Yes & 100 & $\mathbf{1 0 0}$ & \\
& No & 0 & $\mathbf{1 0 0}$ &
\end{tabular}

Source: Own survey (2015) ${ }^{* * * ; * *}$ means statistically significant at $1 \%$ and $5 \%$.

Findings showed that farmers who support the promotion of no-till CA had higher maize yields compared to those who did not support no-till CA promotion. Positive perceptions show readiness of the farmer to accept the technology and learn. It also determines the level of commitment that the farmer will put into their no-till CA farming, which affects their output. Further analysis confirmed this finding with farmers who adopted no-till CA and had positive perceptions of CA promotion by having higher maize yields compared to those who had negative perceptions of its promotion.

\subsection{Why Do Farmers Adopt No-Till CA?}

In order to isolate and determine the factors influencing the adoption of no-till CA in Zashuke, this study was informed by the work of Knowler and Bradshaw [39]. Knowler and Bradshaw [39] reviewed several studies on farmers' adoption of CA and highlighted numerous factors that have an effect on the adoption of the technology.

The binary logistic model included some of the factors that were identified by Knowler and Bradshaw [39] as having a significant influence on farmers' adoption of conservation agriculture, but was also guided by the availability of data and the scope of this study. Table 3 shows the results of the binary logistic regression used to determine factors that were identified to significantly influence the adoption of no-till CA. The results show that factors associated with the adoption of no-till CA 
technology were the frequency of extension worker visits, the perception of no-till CA promotion, the age of the farmer, the level of education and the total cultivated land in hectare (ha).

Table 3. Estimates of the binary logit model.

\begin{tabular}{|c|c|c|c|c|c|c|}
\hline Variable & Coefficients & Odds Ratio & Std. Err. & $z$ & $P>z$ & VIF \\
\hline Constant & -5.528 & 0.004 & 0.008 & -2.75 & 0.006 & \\
\hline Gender & -0.390 & 0.677 & 0.278 & -0.95 & 0.343 & 1.14 \\
\hline Age & $0.065^{* * *}$ & 1.067 & 0.026 & 2.64 & 0.008 & 2.05 \\
\hline Education (schooling years) & $0.194^{* *}$ & 1.214 & 0.113 & 2.09 & 0.037 & 2.34 \\
\hline Farm size cultivated & $-0.272 *$ & 0.762 & 0.115 & -1.81 & 0.071 & 1.07 \\
\hline Income & 0.000 & 1.000 & 0.000 & 1.63 & 0.104 & 1.4 \\
\hline \multicolumn{7}{|l|}{ Frequency of extension visits } \\
\hline Once a month & $1.911 * *$ & 6.762 & 5.091 & 2.54 & 0.011 & 1.87 \\
\hline Twice a month & $1.711^{* *}$ & 5.539 & 4.171 & 2.27 & 0.023 & 2.08 \\
\hline Three or more times a month & $3.284^{* * *}$ & 26.697 & 19.963 & 4.39 & 0.000 & 2.3 \\
\hline Economically active ratio & -0.257 & 0.774 & 0.681 & -0.29 & 0.771 & 1.21 \\
\hline \multicolumn{7}{|l|}{$\begin{array}{l}\text { Perceptions of farmers on } \\
\text { no-till CA promotion }\end{array}$} \\
\hline Agree & -0.812 & 0.444 & 0.238 & -1.51 & 0.131 & 2.01 \\
\hline Neutral & - & 1.000 & - & - & - & 1.3 \\
\hline Disagree & -0.121 & 0.886 & 0.551 & -0.19 & 0.846 & 1.74 \\
\hline Strongly disagree & $-2.810 * * *$ & 0.060 & 0.055 & -3.06 & 0.002 & 1.53 \\
\hline
\end{tabular}

The binary logistic regression model results show that the age variable holding all other things constant is an important factor influencing the no-till CA adoption decisions. The variable age of the farmer positively influenced no-till CA adoption and was statistically significant at the $5 \%$ significance level $(p=0.008)$. The coefficient of the age of the farmer was positively associated with the adoption of no-till CA, which indicates the receptiveness toward technology among the older farmers. An additional year in the age of the farmer increased the log odds of adopting no-till CA (versus non-adoption) by about 1.06 (odds ratio $=1.067$ ) times. This finding is interesting since there is only a slight and insignificant difference in the mean age between the adopters and non-adopters of no-till CA. This suggests some other patterns of potential interest, for example, as revealed earlier in the descriptive statistics section, that adopters of no-till conservation had a higher mean level of education when compared to non-adopters. Again, the more educated farmers tended to be younger than the less educated farmers. Among the more educated farmers, the older farmers would have a higher tendency of adoption. Adoption of the technology by the older farmers may be attributable to the fact that older people may have had better access to resources (for example, land ownership), coupled with experience and knowledge that had been gained over time compared to younger farmers. These results confirmed findings from the work of Nyambose and Jumbe [40]. However, [36,46] provided contrary evidence to this finding, the former arguing that older farmers were accustomed to conventional methods of farming and were unlikely to change.

The variable of the farm size cultivated significantly and negatively influenced the adoption of no-till CA. Larger pieces of land were associated with farmers being less likely to adopt the no-till CA technology, in comparison to the group of farmers with a smaller land size. With a unit increase in the land (an additional hectare of land), the results showed that such farmers were about $33.8 \%$ (odds ratio $=0.762$ ) less likely to adopt no-till CA. This could be because farming is usually regarded as a lesser-desired profession and those with nonfarm jobs tend to lease their land to others. Again, management practices may not be sustainable on larger pieces of land. Although CA does not need to use more labour, these results are explainable in the sense that farmers could have perceived that 
larger tracts of land may be associated with more farm labour requirements and increased weeds especially in the absence of herbicides. Again, there may be increased demand for labour in CA in the initial stages, especially in residue transfer and in adjusting to the system. This emphasis is supplemented by $[17,29,47]$ who concur that farmers utilizing small farm sizes are more likely to adopt new technologies. This may possibly be to maximize land utilization of their small farm sizes under cultivation. On the contrary, larger tracts of land may also influence adoption as stipulated by $[36,40]$.

Although this study excluded dis-adopters, which may result in biased results towards extension visits (as part of the being the Dryland Maize Project) being linked with adoption, the extension is a very important aspect in explaining adoption decisions. The variable frequency of extension worker visits was categorized into four groups. Results in Table 3 show three odds ratios, each describing a relationship with the adoption of CA. The reference was the odds of a farmer having no visits from a local extension worker. The results show that farmers who reported an extension visit once a month had nearly seven (odds ratio $=6.762$ ) times the odds of adopting the technology (statistically significant at $5 \%$ significance level $(p=0.011)$ ). In the same way, farmers who reported an extension visit of twice a month and more than 3 times per month have higher odds of adopting no-till CA of about 5.5 times (odds ratio $=5.539)$ (statistically significant at $5 \%$ significance level $(p=0.023)$ ) and about 26.7 times (odds ratio $=26.697$ ) (statistically significant at $1 \%$ significance level $(p=0.000)$ ), respectively, than those with no extension worker visits. The findings are consistent with the work of $[40,48]$. Therefore, farmers who have more frequent visits from extension workers are more likely to adopt technologies or farming practices that they are exposed to through extension services. In this case, frequent extension services increased the odds of a farmer adopting conservation agriculture as a farming practice.

Results show that the variable perceptions of farmers on no-till CA promotion were negatively related to the likelihood of a farmer adopting no-till CA. Perceptions on no-till CA promotion were measured on a Likert scale, which was categorized into five categories (1, strongly agree; 2, agree; 3 , neutral; 4 , disagree; and 5 , strongly disagree). As the scale increased, perceptions on the promotion of no-till CA became negative. The base category in the model was the odds of a farmer having a very positive perception of no-till promotion; strongly agreeing to no-till CA promotion. Results in Table 3 show that farmers who had a very negative perception regarding the promotion of no-till CA, strongly disagreeing with no-till CA promotion, were less likely to adopt no-till CA by about $94 \%$ (odds ratio $=0.060$ ) (statistically significant at $1 \%$ level $(p=0.002)$ ) compared to farmers who strongly agreed with no-till CA promotion. This shows that as farmers' perceptions on no-till CA promotion changed in a positive way, they were more likely to adopt the technology. These results confirm findings by $[25,49]$ who found that farmers' perceptions had an effect on the adoption of agricultural technologies. The finding is also in harmony with the descriptive analysis showing that farmers who supported the promotion of no-till CA had higher maize yields compared to those who did not support no-till CA promotion, suggesting that the farmers' perceptions could be linked to the level of crop success or failure experienced by the farmers.

The variable number of years in education of the farmer positively influenced the adoption of no-till CA (statistically significant at $5 \%$ significance level $(p=0.037)$ ). An additional year of education attained by the farmer is associated with the log odds of adopting no-till CA (versus non-adoption) increasing by about 1.2 (odds ratio $=1.214$ ) times. These findings are consistent with other studies, such as the work by $[28,40,50]$. Nakhumwa [51] argued that education is a helpful tool for farmers in analyzing choices and making decisions about forecasts of the anticipated benefits of adopting technologies.

\section{Conclusions}

The limited involvement of young people in small-scale farming poses a threat to the sustainability of new methods of farming practices such as no-till CA. Van Niekerk et al. [52] stated that one of the problems in small-scale farming is the lack of involvement of young people in the sector. In farming, 
knowledge has been handed from generation to generation through the elderly teaching the young people their traditions. Thus, it is important to assess how small-scale farmers view no-till CA. Acceptance of the technology as a new farming method in the community will have an impact on its continued promotion and existence in the community. The study has shown the importance of extension contacts in promoting new farming technologies. It managed to show that extension access alone is not enough; the intensity of the extension services is critical in determining the level of adoption. Working with the elderly with limited formal education can be a challenge when introducing new concepts such as no-till CA. Their minds are usually willing but some elderly might be slow in grasping all of the technical issues in the new technology. This points to the need for increased extension contacts between the extension agents and the farmer. Farmers with positive perceptions of no-till CA are more likely to adopt the technology and be committed to seeing it succeed on their farms. Perceptions are part of the psychological capital of an individual and those farmers who have positive attitudes and are long-term focused will adopt no-till CA technologies.

Based on the findings of this study, it is important to make considerations in targeting larger households and older farmers who are more likely to be adopters of no-till CA. However, the attitudes of young people towards farming need to be changed, and conditions need to be created that support their entry into farming at an early stage of their lives. This means that the curriculum at the school level (both lower and higher learning) and lucrative job opportunities in the sector should be geared towards creating this interest. Coupled with support at the household level, an environment can be created where new farming methods such as no-till CA are not only adopted but are sustained from generation to generation. Increasing extension contact with farmers is important in influencing the adoption of CA. More young people need to be trained as extension agents. This can be achieved by providing resources for higher learning institutions to produce quality agents and by marketing the extension advisory services to young people as a lucrative job.

To enhance the adoption of no-till CA, there is a need to change the farmers' mindsets and perceptions of new farming methods in small-scale farming communities. The study has shown that negative perceptions are associated with decreased likelihood of adopting no-till CA. Again, the descriptive analysis shows that positive perceptions are associated with increased yields. Thus, there is a need to train farmers on no-till CA technology to improve their appreciation of the methods, especially in areas where farmers have limited opportunities for and exposure to formal education. The extension information needs to be carefully packaged and disseminated in a way that is understood by even those with little formal education. In addition, refresher training should be supported to the extent that the technology is accepted as the norm and the benefits are appreciated by all in the community.

Acknowledgments: The authors are grateful to the University of Zululand Research and Innovation Office for motivational support towards the final outcome of this work.

Author Contributions: Njabulo Lloyd Ntshangase developed the concept and framework for the study and carried out data collection as part of his MSc dissertation requirement. Brian Muroyiwa compiled the draft manuscript from the MSc dissertation and Melusi Sibanda supervised and verified the scholastic depth of the manuscript. All authors contributed to the discussion and final outcome of the manuscript.

Conflicts of Interest: The authors declare no conflict of interest.

\section{References}

1. Gattinger, A.; Jawtusch, J.; Müller, A.; Mäder, P. No-Till Agriculture-A Climate Smart Solution? Misereor: Aachen, Germany, 2011; pp. 1-24.

2. Manley, J.; Van Kooten, G.C.; Moeltner, K.; Johnson, D.W. Creating carbon offsets in agriculture through no-till cultivation: A meta-analysis of costs and carbon benefits. Clim. Chang. 2005, 68, 41-65. [CrossRef]

3. Luo, Z.; Wang, E.; Sun, O.J. Can no-tillage stimulate carbon sequestration in agricultural soils? A meta-analysis of paired experiments. Agric. Ecosyst. Environ. 2010, 139, 224-231. [CrossRef] 
4. Rockstrom, J. Water resources management in smallholder farms in Eastern and Southern Africa: An overview. Phys. Chem. Earth Part B Hydrol. Oceans Atmos. 2000, 25, 275-283. [CrossRef]

5. Nyamadzawo, G.; Nyamugafata, P.; Wuta, M.; Nyamangara, J.; Chikowo, R. Infiltration and runoff losses under fallowing and conservation agriculture practices on contrasting soils, Zimbabwe. Water SA 2012, 38, 233-240. [CrossRef]

6. Binns, P. UNEP Perspectives Issue No. 5: Opportunities and Challenges Facing Farmers in Transitioning to a Green Economy Agriculture Practice. Available online: https:/ /www.ecolex.org/details/literature/ unep-perspectives-issue-no5-opportunities-and-challenges-facing-farmers-in-transitioning-to-a-greeneconomy-agriculture-practice-mon-086668 / (accessed on 28 November 2017).

7. Blein, R.; Bwalya, M.; Chimatiro, S.; Faivre-Dupaigre, B.; Kisira, S.; Leturque, H.; Wambo-Yamdjeu, A. African Agriculture, Transformation and Outlook; NEPAD (New Partnership for African Development): Lusaka, Zambia, 2013; pp. 3137-3146.

8. Alvarez, R. A review of nitrogen fertilizer and conservation tillage effects on soil organic carbon storage. Soil Use Manag. 2005, 21, 38-52. [CrossRef]

9. Chase, P.; Singh, O.P. Soil Nutrients and Fertility in Three Traditional Land Use Systems of Khonoma, Nagaland, India. Resour. Environ. 2014, 4, 181-189. [CrossRef]

10. Govaerts, B.; Sayre, K.D.; Goudeseune, B.; De Corte, P.; Lichter, K.; Dendooven, L.; Deckers, J. Conservation agriculture as a sustainable option for the central Mexican highlands. Soil Tillage Res. 2009, 103, 222-230. [CrossRef]

11. Derpsch, R.; Benites, J. Situation of conservation agriculture in the world. World Congr. Conserv. Agric. 2003, $2,67-70$.

12. Wall, P.C. Experiences with crop residue cover and direct seeding in the Bolivian highlands. Mt. Res. Dev. 1999, 19, 313-317. [CrossRef]

13. Du Toit, G. Promoting Conservation Agriculture in South Africa: A Case Study among Commercila Grain Producers in the North West Province; The Bureau for Food and Agricultural Policy (BFAP): Pretoria, South Africa, 2007.

14. Department of Agriculture Forestry and Fisheries. A Framework for the Development of Smallholder Farmers through Cooperative Development; Department of Agriculture Forestry and Fisheries: Pretoria, South Africa, 2012; pp. 1-8.

15. Du Preez, C.C.; Van Huyssteen, C.; Mnkeni, P. Land use and soil organic matter in South Africa 2: A review on the influence of arable crop production. S. Afr. J. Sci. 2011, 107, 2-9. [CrossRef]

16. Food and Agriculture Organization. Guidelines and Reference Material on Integrated Soil and Nutrient Management and Conservation for Farmer Field Schools; Food and Agriculture Organization: Rome, Italy, 2000.

17. Lugandu, S. Factors Influencing the Adoption of Conservation Agriculture by Smallholder Farmers in Karatu and Kongwa Districts of Tanzania-Google Books. Available online: https://books.google.co.ls/books/ about/Factors_Influencing_the_Adoption_of_Cons.html?id=n-e7jgEACAAJ\&redir_esc=y (accessed on 30 November 2017).

18. Enfors, E. Traps and Transformations: Exploring the Potential of Water System Innovations in Dryland Sub-Saharan Africa; Stockholm University: Stockholm, Sweden, 2009.

19. Alemu, M.M. Sustainable Land Management. J. Environ. Prot. 2016, 7, 502-506. [CrossRef]

20. Mcrobert, J.; Rickards, L. Social research: Insights into farmers' conversion to no-till farming systems. Ext. Farming Syst. J. 2010, 6, 43-52.

21. Sheikh, A.D.; Rehman, T.; Yates, C.M. Logit models for identifying the factors that influence the uptake of new "no-tillage" technologies by farmers in the rice-wheat and the cotton-wheat farming systems of Pakistan's Punjab. Agric. Syst. 2003, 75, 79-95. [CrossRef]

22. D'Emden, F.H.; Llewellyn, R.S.; Burton, M.P. Factors influencing adoption of conservation tillage in Australian cropping regions. Aust. J. Agric. Resour. Econ. 2008, 52, 169-182. [CrossRef]

23. Ingwe Municipality. Ingwe Draft Annual Report; Ingwe Municipality: KwaZulu Natal, South Africa, 2013.

24. Ingwe Municipality. Ingwe Annual Report; Ingwe Municipality: KwaZulu Natal, South Africa, 2014.

25. Adesina, A.A.; Zinnah, M.M. Technology characteristics, farmers' perceptions and adoption decisions: A Tobit model application in Sierra Leone. Agric. Econ. 1993, 9, 297-311. [CrossRef]

26. Rogers, E.M. Diffusion of Innovations, 5th ed.; Free Press: Washington, DC, USA, 2003; ISBN 0743258231.

27. Feder, G.; Just, R.E.; Zilberman, D. Adoption of Agricultural Innovation in Developing Countries: A Survey; University of Chicago Press: Chicago, IL, USA, 1985; Volume 33, ISBN 0821301039. 
28. Bisangwa, E. The Influence of Conservation Agriculture Adoption on Input Demand and Maize Production in Butha Buthe, Lesotho. Master's Thesis, University of Tennessee, Knoxville, TN, USA, 2013.

29. Kassam, A.H.; Mkomwa, S.; Friedrich, T. Conservation Agriculture for Africa: Building Resilient Farming Systems in a Changing Climate; CABI: Wallingford, UK; Boston, MA, USA, 2017; ISBN 1780645686.

30. Daniel, C.N.; Berinyuy, L.P. Using the SERVQUAL Model to assess Service Quality and Customer Satisfaction. An Empirical Study of Grocery Stores in Umea. Master's Thesis, Umeå University, Umeå, Sweden, 2010.

31. Bryman, A.; Bell, E. Business Research Methods; Ventus Publishing: Copenhagen, Denmark, 2007; ISBN 978-0199284986.

32. Hardon, A.; Hodgkin, C.; Fresle, D. How to Investigate the Use of Medicines by Consumers; World Health Organization: Geneva, Switzerland; University of Amsterdam: Amsterdam, The Netherlands, 2004; pp. 1-98. [CrossRef]

33. Krejcie, R.V.; Morgan, D.W. Determining Sample Size for Research Activities Robert. Educ. Psychol. Meas. 1970, 38, 607-610. [CrossRef]

34. Pautsch, G. The efficiency of sequestering carbon in agricultural soils. Contemp. Econ. Policy 2001, 19, $123-134$. [CrossRef]

35. Somda, J.; Nianogo, A.J.; Nassa, S.; Sanou, S. Soil fertility management and socio-economic factors in crop-livestock systems in Burkina Faso: A case study of composting technology. Ecol. Econ. 2002, 43, 175-183. [CrossRef]

36. Nyanga, P.H. Factors Influencing Adoption and Area under Conservation Agriculture: A Mixed Methods Approach. Sustain. Agric. Res. 2012, 1, 27-40. [CrossRef]

37. Agresti, A. An Introduction to Categorical Data Analysis; John Wiley \& Sons, Inc.: Hoboken, NJ, USA, 2007; ISBN 9780471226185.

38. Greene, W.H. Econometric Analysis; Prentice Hall: Upper Saddle River, NJ, USA, 2003; Volume 97, ISBN 0130661899.

39. Knowler, D.; Bradshaw, B. Farmers' adoption of conservation agriculture: A review and synthesis of recent research. Food Policy 2007, 32, 25-48. [CrossRef]

40. Nyambose, W.; Jumbe, C. Does Conservation Agriculture Enhance Household Food Security? Evidence from Smallholder Farmers in Nkhotakota in Malawi. Sustain. Agric. Res. 2013, 5, 118-128. [CrossRef]

41. Pillay, N.K.; Maharaj, P. Aging and Health in Africa; Springer: New York, NY, USA, 2013; ISBN 978-1-4419-8356-5.

42. Statistics South Africa. Census 2011: Profile of Older Persons in South Africa; Statistics South Africa: Pretoria, South Africa, 2014; ISBN 9780621427943.

43. Bationo, A.; Waswa, B.; Kihara, J.; Kimetu, J. Advances in Integrated Soil Fertility Management in Sub-Saharan Africa: Challenges and Opportunities; Springer: New York, NY, USA, 2007; pp. 201-208. [CrossRef]

44. Nguthi, F. Adoption of Agricultural Innovations by Smallholder Farmers in the Context of HIV/AIDS: The Case of Tissue-Cultured Banana in Kenya. Ph.D. Thesis, Wageningen University, Wageningen, The Netherlands, 2007.

45. Kahimba, F.C.; Mutabazi, K.D.; Tumbo, S.D.; Masuki, K.F.; Mbungu, W.B. Adoption and Scaling-Up of Conservation Agriculture in Tanzania: Case of Arusha and Dodoma Regions. Nat. Resour. 2014, 5, 161-176. [CrossRef]

46. Arellanes, P.; Lee, D.R. The determinants of adoption of sustainable agriculture technologies: Evidence from the hillsides of Honduras. In Proceedings of the 25th International Conference of Agricultural Economists (IAAE), Durban, South Africa, 16-22 August 2003; pp. 693-699.

47. Adeola, R.G. Influence of Socio-Economic Factors on the Adoption of Soil Conservation Measures in Ibadan/Ibarapa Agricultural Zone of Oyo State. Rep. Opin. 2010, 2, 42-47.

48. Arslan, A.; McCarthy, N.; Lipper, L.; Asfaw, S.; Cattaneo, A. Adoption and intensity of adoption of conservation farming practices in Zambia. Agric. Ecosyst. Environ. 2014, 187, 72-86. [CrossRef]

49. Adesina, A.A.; Baidu-Forson, J. Farmers' perceptions and adoption of new agricultural technology: Evidence from analysis in Burkina Faso and Guinea, West Africa. Agric. Econ. 1995, 13, 1-9. [CrossRef]

50. Langyintuo, A.S.; Mekuria, M. Accounting for neighborhood influence in estimating factors determining the adoption of improved agricultural technologies. In Proceedings of the American Agricultural Economics Association Annual Meeting, Providence, RI, USA, 24-27 July 2005; pp. 1-28. 
51. Nakhumwa, T.O.; Hassan, R.M. Optimal Management of Soil Quality Stocks and Long-Term Consequences of Land Degradation for Smallholder Farmers in Malawi. Environ. Resour. Econ. 2012, 52, 415-433. [CrossRef]

52. Van Niekerk, J.A.; Stroebel, A.; van Rooyen, C.J.; Whitfield, K.P.; Swanepoel, F.C.J. Towards redesigning the Agricultural extension service in South Africa: Views and proposals of extensionists in the Eastern Cape. S. Afr. J. Agric. Ext. 2011, 39, 57-68. 